\title{
DESIGN OF HOLLOW SECTION OVERLAP JOINTS WITH THE REINFORCING RIB PLATE. WELDED CONNECTION RESISTANCE
}

\author{
J. BRÓDKA ${ }^{1}$, M. BRONIEWICZ ${ }^{2}$
}

\begin{abstract}
In calculating the resistance of welds within the connections between hollow sections in EN 1993-1-8, very general information is given without presenting specific calculations. The chief recommendations indicate that the resistance of the welds connecting the wall to the second element should not be less than the resistance of the cross section of the wall. In addition, assessment of the welds' resistance based on the effective lengths is viable in cases when forces in the braces are smaller than the resistance of the joint, though the detailed method was not specified. The objective of this paper is to present the most up-to-date information about the design of overlap welded joints with a reinforcing rib plate.
\end{abstract}

Keywords: steel structures, hollow sections, reinforced overlap joints, weld resistance

\section{INTRODUCTION}

The basic shapes of joints with a reinforcing rib between the braces are shown in Figure 1 in the case where trusses are made of square hollow sections. In relatively rare cases rectangular hollow sections are also used, but the geometry of the joints remains the same. Mostly, the braces are the same in width and height. Depending on the kind of truss, the angles of inclination of the axis of the braces are different. The joints made of circular hollow sections are shaped similarly, though sometimes with minor changes.

\footnotetext{
${ }^{1}$ Professor Emeritus in Bialystok University of Technology, ul .Wiejska 45, 15-351 Białystok, e-mail: jan.brodka@gmail.com

${ }^{2}$ Faculty of Civil and Environmental Engineering, Białystok University of Technology, ul .Wiejska 45, 15-351 Białystok, e-mail: m.broniewicz@pb.edu.pl
} 
Fig. 1a shows the solution of the joints when the depth $h_{l}$ of the braces is less than the depth of the chord, in which case the eccentricity is generally negative and equal: $0,35 \mathrm{~h}_{0} \leq \mathrm{e} \leq-0,55 \mathrm{~h}_{0}\left(\mathrm{~h}_{0}-\right.$ the depth of the chord) or $-0,35 \mathrm{~d}_{0} \leq \mathrm{e} \leq-0,55 \mathrm{~d}_{0}\left(\mathrm{~d}_{0}-\right.$ the diameter of the chord). In contrast, Fig. $1 \mathrm{~b}$ shows an example of the joint where the depth of the chord and the braces are nearly the same and the eccentric was not designed. In turn, in Fig.1c the solution with the equal depth of braces and chord is presented. For the overlap of the braces to not be too high, the eccentricity should be positive and stay within range of $0 \leq \mathrm{e} \leq 0,25 \mathrm{~h}_{0}$. The thickness of the rib depends on the values of the forces in the braces and is usually $1,5 \mathrm{t}_{0} \leq \mathrm{t}_{\mathrm{p}} \leq 2 \mathrm{t}_{0}$ but at least $10 \mathrm{~mm}$ ( $\mathrm{t}_{0}$ - the wall thickness of the chord).

a)

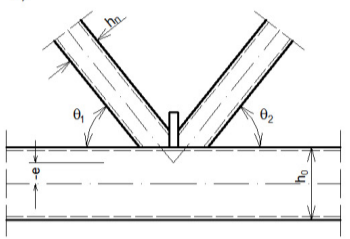

b)

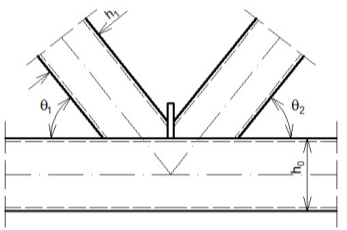

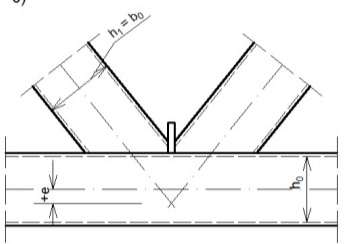

Fig. 1. Joints of trusses made of square hollow sections with a reinforcing rib plate

It should be considered that a joint made of circular hollow sections where the diameters of the braces in the splice with the chord are the same, that is, when $d_{1}=d_{0}\left(d_{1}\right.$ is the diameter of the brace and $d_{0}$ the diameter of the chord). This is shown in Fig. 2. When connecting the brace with the chord it is impossible to execute butt or fillet welds along the entire length, such as the lengths near the plane perpendicular to the rib, located in the axis of the chord. The brace, after cutting along a spatial curve takes the form of a sharp beak. The tip of this length must be cut in a way that makes it possible to arrange the fillet weld at the desired thickness. In Fig. 2 the geometry of the splice is shown as a straight line parallel to the chord.

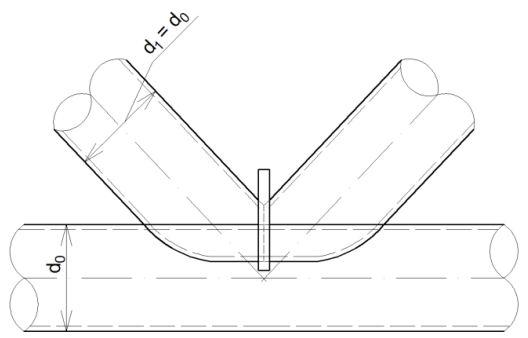

Fig. 2. Typical joint made of circular hollow sections with a reinforcing rib 
The method of calculation of the welds' resistance within the connections between the hollow sections presented in EN 1993-1-8 is very general, and without indicating specific calculation procedures. The publication mentioned in the references contains only fragmentary information in relation to gap joints.

As presented in publications [2] and [3] the procedures for assessing the resistance of fillet welds of $\mathrm{T}, \mathrm{Y}, \mathrm{X}$ and gap $\mathrm{K}, \mathrm{N}$ types of joints made from hollow sections have been developed. Consequently, in publication [4] the method of design for overlapping $\mathrm{K}$ and $\mathrm{N}$ joints is also presented. In all these types of joints fillet welds are used, with their effective lengths determined on the basis of experimental research or design guidelines presented in EN 1993-1-8 [9],though in the latter, the design of these lengths are not provided explicitly.

In EN 1993-1-8 [9] the calculation of the joints with fillet or groove welds with effective weld length is allowed in cases when: the forces in the braces are less than the resistance of the joint, instability of the braces could occur, or when unifying the range of truss elements. Such situations are commonly found and both designers and contractors need to be aware of them.

The procedures used for assessing the weld resistance suggested by the authors are complex and quite tedious. In EN 1993-1-8 [9], very simple recommendations for the calculating of fillet welds are given, which improve the speed of the design, but lead to increased labour during fabrication, as well as an increase in shrinkage stress.

Nevertheless, no information regarding the assessment of the thickness of groove welds is given. In order to simplify the evaluation of weld resistance, the design resistance of the weld per unit length of the perimeter of a brace member should not normally be less than that member's design resistance of the cross section per unit length of the perimeter.

This recommendation will be satisfied when full butt welds or fillet welds are used with a thickness in which their resistance is equivalent to the capacity of the joining members. For practical purposes, a maximum thickness of welds is given, depending on the steel grade of the joint members.

$$
\begin{array}{ll}
\text { steel } \mathrm{S} 235 \mathrm{H}: & a_{w}=0,903 t_{1}, \\
\text { steel S275H: } & a_{w}=0,986 t_{1}, \\
\text { steel S355H: } & a_{w}=1,176 t_{1}, \\
\text { steel S420H: } & a_{w}=1,397 t_{1},
\end{array}
$$

where: 
$a_{w}$ - greatest thickness of fillet weld,

$t_{l} \quad$ - wall thickness of the hollow section.

In paper [1] it was indicated that in the evaluation of the joint resistance with a reinforcing rib plate, the formulas given in EN 1993-1-8 can be used, with regard to the overlap joints. That indication cannot be extended to assess the resistance of the fillet welds of the joints with stiffening rib plates because of the different layout of welds on the ends of the braces. It should be noted that with regard to the standard condition, the weld resistance per unit length of a brace perimeter was generally not less than the brace member capacity, which is not always possible. Such situations occur in following design situations:

a) In the cases shown in Figure 2, in which the full penetration butt weld on the w length of the connection cannot be designed.

b) When the braces and the chord have the same cross sectional dimensions.

\section{THE RESISTANCE OF CONNECTION}

If, in the connection, the fillet welds are used of a thickness according to (1.1), their resistance will be equivalent to the resistance of full butt welds. In this case, checking the connection resistance is unnecessary. The only exception was the checking of the welds in areas of overlapping braces made up of rectangular and circular hollow sections. This however, was not explained. The corresponding formulas are given in the IIW Recommendations [12], as well as in BS ISO 14346 [6], which were developed on the basis of these guidelines.

The IIW Recommendations [12] and the draft of ISO standard [6] provided a way to evaluate the capacity of the connection with regard to the plane of splice cross-bracings with the chord in the case of K type joints, where cross-bracings overlap each other partially or completely. Checking the shear of full penetration butt weld (and equivalent fillet weld) is carried out as follows:

- in the case of square or rectangular hollow sections, the resistance for K overlap joints in the plane of splice of cross-bracings with the chord is checked as follows:

a) when $\lambda_{o v, \lim }<\lambda_{o v}<100 \%$ :

$$
N_{i} \cos \theta_{i}+N_{j} \cos \theta_{j} \leq\left(0,58 f_{u i} \frac{\left(2 h_{i, r e d}+b_{i, \text { eff }}\right) \cdot t_{i}}{\sin \theta_{i}}+0,58 f_{u j} \frac{\left(2 h_{j}+c_{s} b_{j, e f f}\right) \cdot t_{j}}{\sin \theta_{j}}\right) / \gamma_{M 5}
$$


b) when $\lambda_{o v}=100 \%$ :

$$
N_{i} \cos \theta_{i}+N_{j} \cos \theta_{j} \leq 0,58 f_{u j} \frac{\left(2 h_{j}+b_{j}+b_{j, e f f}\right) \cdot t_{j}}{\sin \theta_{j}} / \gamma_{M 5},
$$

where:

$N_{i}, N_{j}$ - design axial load in the overlapping and the overlapped braces respectively, $\theta_{i}, \theta_{j}$ - angles of overlapping and overlapped braces respectively in relationship to the chord, $f_{u i}, f_{u j}$ - the tensile strength of overlapping and overlapped braces respectively, provided that $f_{u i} \leq f_{u 0}$ and $f_{u j} \leq f_{u 0}\left(f_{u 0}\right.$ - yield strength of the steel used in the chord),

$h_{i, \text { red }}=\left(100-\lambda_{o v}\right) h_{i} \cdot 100 \%$,

$b_{i}, h_{i}$ - the width and the depth of cross section respectively of the overlapping brace,

$b_{j}, h_{j}$ - the width and the depth of cross section respectively of the overlapped brace,

$t_{i}, t_{j}$ - the wall thickness of the overlapping and the overlapped brace respectively,

$t_{0}$ - the wall thickness of the chord,

$b_{0}$ - the width of the chord section,

$f_{y 0}, f_{y i}, f_{y j}$ - the yield strength of the chord, overlapping and overlapped braces respectively.

$\lambda_{o v}=\left(\frac{q}{p}\right) \cdot 100 \%$ - the overlap ratio according to EN 1993-1-8 [9], and [1], [4], [5].

- in relation to the circular hollow sections it is necessary to check the value of the force component in the plane of splice of the cross-bracings with the chords [6] and [12]:

a) when $\lambda_{o v, \lim }<\lambda_{o v}<100 \%$ :

$$
N_{i} \cos \theta_{i}+N_{j} \cos \theta_{j} \leq 0,25 \pi\left(0,58 f_{u i} \frac{\left(2 d_{i, r e d}+d_{i, e f f}\right) \cdot t_{i}}{\sin \theta_{i}}+0,58 f_{u j} \frac{\left(2 d_{j}+c_{s} d_{j, e f f}\right) \cdot t_{j}}{\sin \theta_{j}}\right) / \gamma_{M 5}
$$

b) when $\lambda_{o v}=100 \%$ :

and additionally:

$d_{i, r e d}=\left(100-\lambda_{o v}\right) d_{i} \cdot 100 \%$, but $\lambda_{o v} \mathrm{~W} \%$,

$d_{i}, d_{j}$ - the relative diameter of the circular overlapping and overlapped braces,

$d_{i, e f f}, d_{j, e f f}-$ the effective relative width of the circular overlapping and overlapped braces:

$d_{j, e f f}=\frac{12}{d_{0} / t_{0}} \frac{f_{y 0} t_{0}}{f_{y j} t_{j}} d_{j}$, but $d_{j, e f f} \leq d_{j}$, 
$d_{i, e f f}=\frac{12}{d_{0} / t_{0}} \frac{f_{y 0} t_{0}}{f_{y i} t_{i}} d_{i}$, but $d_{i, e f f} \leq d_{i}$,

$\gamma_{M 5}=1,0$.

In the case of $\mathrm{K}$ joints, the hidden seam of the brace with the chord can be welded or left without being welded. This is expressed by the value $\lambda_{o v, \text { lim }}$ and the coefficient $c_{s}$. It is assumed that: $c_{s}=1$ and $\lambda_{o v, \text { lim }}=60 \%$ if the hidden seam of the overlapped brace is not welded,

$c_{s}=2$ and $\lambda_{o v, \lim }=80 \%$ if the hidden seam of the overlapped brace is welded.

\section{THE DESIGN THROAT THICKNESS OF WELDS}

In rectangular hollow section joints, the groove welds are used in cases when the braces and the chord are the same width.

a)

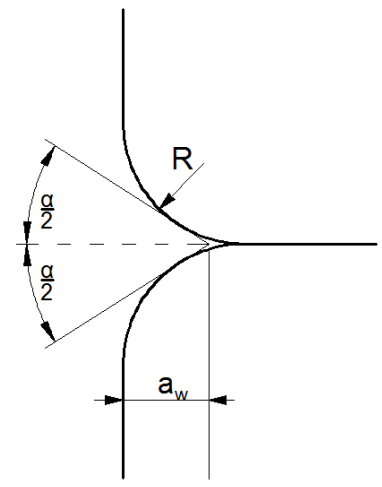

b)

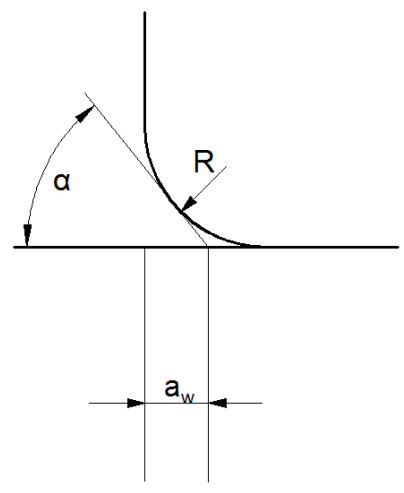

Fig. 3. Throat of groove welds

The standard EN 1090-2 states that in the case of two elements having rounded corners, the thickness of the groove welds between them is determined by angle $\alpha=60$ o (Fig. 3a). It is much more common to see the design of such welds in the corner of the hollow section in splice with a flat element (Fig. $3 b)$. Evaluation of the maximum thickness of such welds is given as follows [5]: 


$$
a_{w}=R[1-\cos \alpha+(1-\sin \alpha) \operatorname{tg} \alpha]
$$

where:

$R \quad$ - the outer diameter of corner of the hollow section.

The thicknesses of the welds are determined by the relationship (2.5):

$$
\text { Fig. 3a: } \quad a_{w}=0,3 \boldsymbol{E} \text {, }
$$

Fig. 3b: $\quad a_{w}=0,42 \boldsymbol{B}$.

By accepting that, according to EN 10210-2 [10], which refers to hot-finished structural hollow sections, where the outer diameter of the corner is equal to $R=t(t-$ width of the wall) the thicknesses of the welds can be determined as follows:

Fig. 3a: $\quad a_{w}=0,73 t$,

$$
\text { Fig. 3b: } \quad a_{w}=0,42 \hat{E} \text {. }
$$

The comparison of the thickness calculated using the formulas (1) and (2.7) shows, that these types of joints do not satisfy standard requirements in terms of the connection with both equal and unequal widths of elements. The EN 10219-2 [11], referring to cold-formed hollow sections, determines that the radii of the corners are:

$$
R=2 t \text { if } t \leq 6 \mathrm{~mm}, R=2,5 t \text { if } 6 \mathrm{~mm}<t \leq 10 \mathrm{~mm}, R=3 t \text { if } t>10 \mathrm{~mm}
$$

On the basis of the comparison of thicknesses of the elements calculated according to (1) and (2.8), we can assess that formula (2.8) is always satisfied in cases when the joints made of hollow sections have the same width, because $a_{w}>2 \cdot 0,735 t=1,7 t$.

However, in the case of joints being between the rectangular hollow sections and the flat plate, every single situation must be analyzed. In a design situation, in which the widths of the sections are the same, and the wall thicknesses are different, four types of joint shapes need to be considered (Fig. 4). 
a)

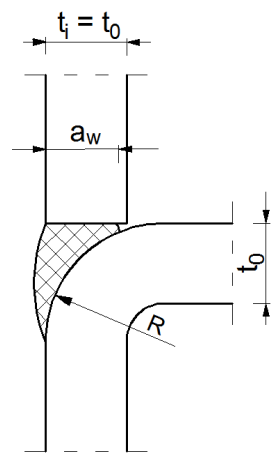

b)

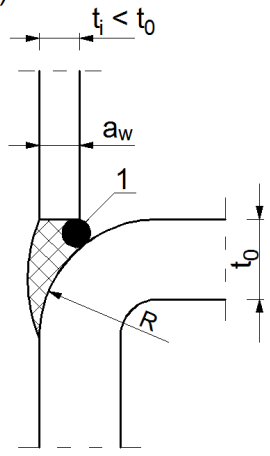

c)

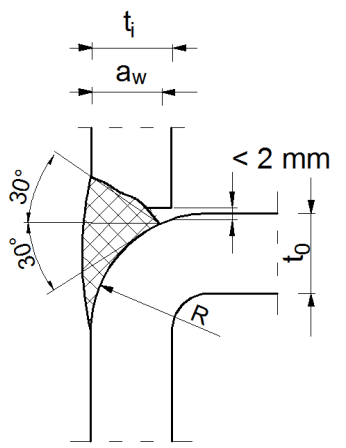

Fig. 4. Design situation of groove welds

In the first situation, the shapes of elements are considered depending on the radius of the corner, the wall thickness of the section and the angle $\alpha=60^{\circ}$ (Fig. $4 \mathrm{a}$ and $4 \mathrm{~b}$ ). Due to the shape of the groove being a result of a rounded corner, the butt weld is blurred. If the joining elements have the same thicknesses as the walls, the spacing in the root is smaller (not larger than $2 \mathrm{~mm}$ ) and the first layer of weld metal cannot flow into the hollow section (Fig. 4a). However, the weld thickness will then be less than the thickness of the wall, as $a_{w}<t_{i}=t_{0}$ and such a weld will be assessed as incomplete. Conversely, if the brace has a wall thickness smaller than the chord with a rounded corner, then the distance in the root will be too large. To lay the first layer of the weld at the root, it is necessary to provide a thin round bar (Fig. 4b). As a result of melting this bar, a weld with the thickness $a_{w}=t_{i}<$ $t_{0}$ is obtained and this is considered to be complete. In the joint discussed we should always obtain $\alpha$ $=60^{\circ}$. In the last case (Fig. 4c); to obtain the desired thickness of the butt weld, a wall is chamfering at an angle of $30^{\circ}$. The angle $\alpha$ then has the required standard value of $60^{\circ}$. Such a weld is also somewhat blurred. The incomplete weld is achieved when $a_{w} \leq 0,735 t_{i}$. The other design situations, as discussed in the examples in Figure 4, due to the shape of cross section of the weld, are unacceptable. The butt welds presented in Figure 4 have had the calculation of their resistance carried out assuming they are being treated as fillet welds.

The angle between the brace and the rib should not be less than $30^{\circ}$ in accordance with the requirements of EN 1993-1-8. If the difference in the width of the joining square or rectangular elements is $b_{0}-b_{j} \approx 1,414 a_{w}+R$ or more, then fillet welds can be applied. When the joints are made of circular hollow sections, the shapes of the welds are blurred, when diameters of braces 
$d_{j}<\approx d_{0} / 3$. Otherwise, a combination of welds is required. These general statements are also valid when we change $b_{i}$ or $d_{i}$ to $b_{j}$ or $d_{j}$, and also $b_{0}$ to $b_{j}$.

\section{PROCEDURE FOR DETERMINING THE STRESSES IN FILLET WELDS}

When examining the stresses in welds, the bending moments are omitted when the eccentricity in a joint has a value of between $e=0,25 h_{0}$ and $e=-0,55 h_{0}$ or $e=0,25 d_{0}$ and $e=-0,55 d_{0}$. These values are consistent with previous Recommendations IIW and are also in EN 1993-1-8 [9].

\subsection{JOINTS MADE OF RECTANGULAR HOLLOW SECTIONS}

\subsubsection{INTERMEDIATE JOINTS}

In order to determine the resistance of the joints, the dimensions of the welds presented in Fig. 5 are considered. In this figure, the dimensions of all the welds in splice of braces with the chord and with the rib are indicated.
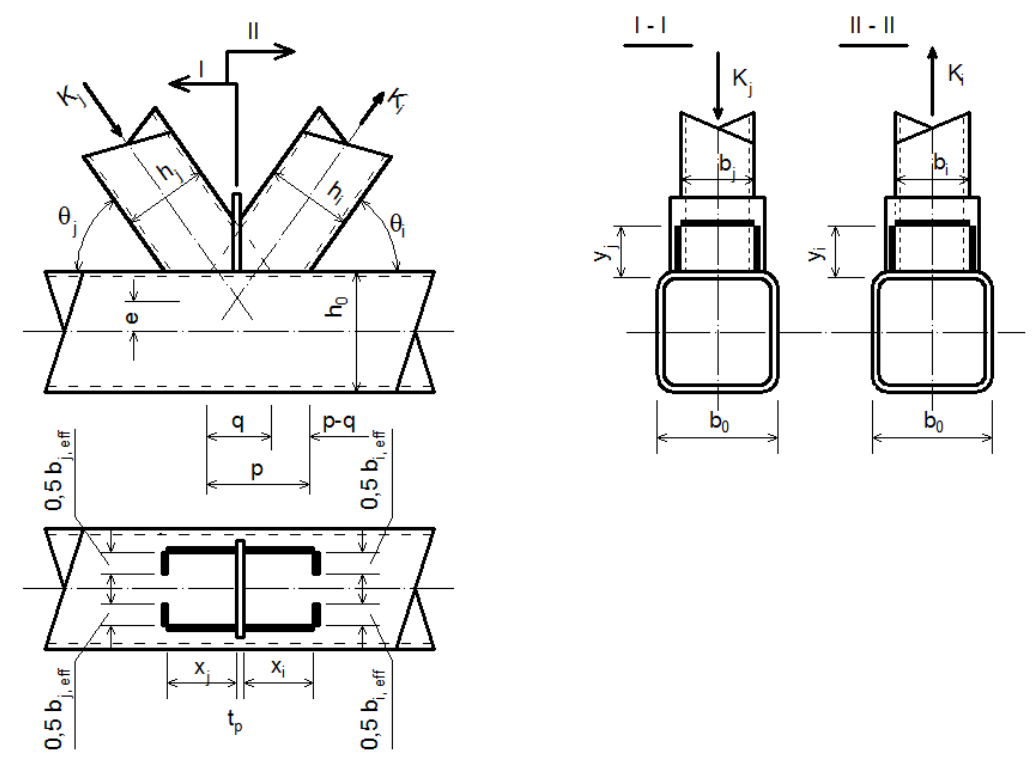

Fig. 5. Square hollow section overlap joint with a reinforcing rib plate 
The length value of the projected contact area between the overlapping brace and chord without the presence of the overlapped brace $q$ is determined in equation (2-1). The value is $p=h_{i} / \sin \theta_{i}$. The lengths of welds $x_{j}$ or $x_{i}$ and $y_{j}$ or $y_{i}$ are determined on the basis of drawing joints on such a scale that the measurement was deemed accurate. Measurement accuracy is checked as follows:

$$
x_{j}+t_{p}+x_{i}=h_{j} / \sin \theta_{j}+p-q,
$$

where:

$h_{j}, \theta_{j}$, - have the meaning as presented in equation (2-1),

$t_{p}$ - the thickness of the rib.

The thickness of the welds may be different for lengths $x_{j}, x_{i}, b_{j, \text { eff, }}, b_{i, e f f,} y_{j}, y_{i}$, and also for $b_{j}$ or $b_{i}$. The thickness shall be determined according to the shapes of the welds, treating them as fillet or groove welds. In Fig. 6, the layout of fillet welds are presented, whereby Fig. 6a refers to joining braces to the chord and Fig. $6 \mathrm{~b}$ refers to joining braces to the rib.

a)

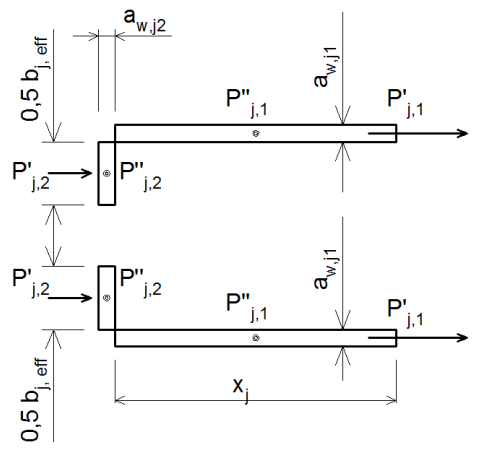

b)

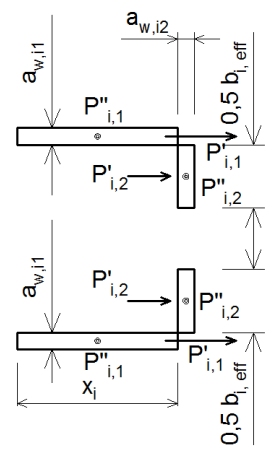

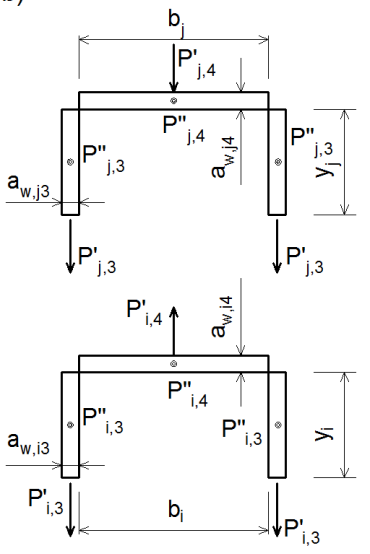

Fig. 6. Cross section welds with effective lengths

To simplify notation, the effective lengths of fillet welds in splice between brace $K_{j}$ and the chord or the rib are expressed as follows:

$$
l_{1}=x_{j}-1,4 a_{w, p}, \quad l_{2}=0,5 b_{j, e f f}, \quad l_{3}=y_{j}-1,4 a_{w, p}, \quad l_{4}=b_{j},
$$

where $a_{w, p}$ is the thickness of the weld joining the rib plate with the chord. 
This weld is involved only in the direct transmission of the forces acting on the rib.

If the sections of the welds are made with different thicknesses, then the cross sections of the welds are:

a) in the splice of the braces $K_{j}$ and $K_{i}$ with the chord:

$$
A_{1}=l_{1} a_{w, j 1}, \quad A_{2}=l_{2} a_{w, j 2},
$$

b) in the splice of the braces $K_{j}$ and $K_{i}$ with the rib:

$$
A_{3}=l_{3} a_{w, j 3}, \quad A_{4}=l_{4} a_{w, j 4} .
$$

In the case of the welds joining the brace loaded by the force $K_{i}$ the indexes ' $j$ ' should be changed to ' $i$ ' and also we should note that the thicknesses of the welds $a_{w, 1}$ to $a_{w, 4}$ may be different, since the thicknesses of the walls loaded by the forces $K_{j}$ and $K_{i}$, may have different values.

The welds are subjected to components of the forces in the braces $K_{j}$ or $K_{i}$ which are parallel or perpendicular to the chord or parallel or perpendicular to the ribs. They are loaded with parts of these forces, depending on the lengths of the welds. The stresses in the welds $\sigma^{\prime}$ and $\sigma^{\prime \prime}$ are calculated by considering whether the direction of the load is parallel or perpendicular.

The component of the force $K_{j} \cos \theta_{j}$ parallel to the chord loads of the chord and the rib acting on welds $A_{1}$ to $A_{4}$ :

$$
K_{j} \cos \theta_{j}=2 P_{1}^{\prime}+2 P_{2}^{\prime}+2 P_{3}^{\prime \prime}+P_{4}^{\prime \prime},
$$

where:

$P_{1}^{\prime}, P_{2}^{\prime}$ - the load parallel to the chord acting on the welds $A_{1}$ and $A_{2}$ respectively, $P_{3}^{\prime \prime}, P_{4}^{\prime \prime}$ - the load perpendicular to the rib acting on the welds respectively $A_{3}$ and $A_{4}$ respectively.

To calculate the values of the components of forces in the welds, the auxiliary ratios are determined as follows:

$$
\alpha_{1}^{\prime}=\frac{P_{2}^{\prime}}{P_{1}^{\prime}} ; \quad \alpha_{3}^{\prime \prime}=\frac{2 P_{4}^{\prime \prime}}{P_{3}^{\prime \prime}} ; \quad \beta_{1}^{\prime}=\frac{P_{3}^{\prime \prime}}{P_{1}^{\prime}} .
$$

Using these ratios we obtain: $P_{1}^{\prime}, P_{2}^{\prime}, P_{3}^{\prime \prime}$ and $P_{4}^{\prime \prime}$ :

$$
\begin{aligned}
& P_{1}^{\prime}=\frac{K_{j} \cos \theta_{j}}{2\left[1+\alpha_{1}^{\prime}+\beta_{1}^{\prime}\left(1+0,25 \alpha_{3}^{\prime \prime}\right)\right]} \\
& P_{2}^{\prime}=\frac{\alpha_{1}^{\prime} K_{j} \cos \theta_{j}}{2\left[1+\alpha_{1}^{\prime}+\beta_{1}^{\prime}\left(1+0,25 \alpha_{3}^{\prime \prime}\right)\right]}
\end{aligned}
$$


(4.1c)

$$
\begin{aligned}
& P_{3}^{\prime \prime}=\frac{\beta_{1}^{\prime} K_{j} \cos \theta_{j}}{2\left[1+\alpha_{1}^{\prime}+\beta_{1}^{\prime}\left(1+0,25 \alpha_{3}^{\prime \prime}\right)\right]} \\
& P_{4}^{\prime \prime}=\frac{\alpha_{3}^{\prime \prime} \beta_{1}^{\prime} K_{j} \cos \theta_{j}}{4\left[1+\alpha_{1}^{\prime}+\beta_{1}^{\prime}\left(1+0,25 \alpha_{3}^{\prime \prime}\right)\right]}
\end{aligned}
$$

whereby the ratios are determined by assuming that $f_{y j} \leq f_{y p}$ and $f_{y j} \leq f_{y o}$ as follows:

$$
\alpha_{1}^{\prime}=\frac{A_{2}}{A_{1}}, \quad \alpha_{3}^{\prime \prime}=\frac{2 A_{4}}{A_{3}}, \quad \text { and } \quad \beta_{1}^{\prime}=\frac{A_{3}}{A_{1}} \text {. }
$$

The component force perpendicular to the chord loads the chord and the rib, acting on sections of welds $A_{1}$ to $A_{4}$ as follows:

$$
K_{j} \sin \theta_{j}=2 P_{1}^{\prime \prime}+2 P_{2}^{\prime \prime}+2 P_{3}^{\prime}+P_{4}^{\prime},
$$

where:

$P_{3}^{\prime}, P_{4}^{\prime}$ - the load parallel to the rib acting on the welds $A_{3}$ and $A_{4}$ respectively, $P_{1}^{\prime \prime}, P_{2}^{\prime \prime}$ - the load perpendicular to the rib acting on the welds $A_{1}$ and $A_{2}$ respectively.

To calculate the values of the components of forces in the welds, the auxiliary ratios can be determined as follows:

$$
\alpha_{1}^{\prime \prime}=\frac{P_{2}^{\prime \prime}}{P_{1}^{\prime \prime}} ; \quad \alpha_{3}^{\prime}=\frac{2 P_{4}^{\prime}}{P_{3}^{\prime}} ; \quad \text { and } \quad \beta_{1}^{\prime \prime}=\frac{P_{3}^{\prime}}{P_{1}^{\prime \prime}} \text {. }
$$

It was found that $\alpha_{1}^{\prime \prime}=\alpha_{1}^{\prime}, \alpha_{3}^{\prime}=\alpha_{3}^{\prime \prime}$ and $\beta_{1}^{\prime \prime}=\beta_{1}^{\prime}$, as the parallel and perpendicular components acted on the same cross sections of the welds, so using these ratios, the forces were determined by the results using the ratios of the forces $P_{1}{ }^{\prime}, P_{2}{ }^{\prime}, P_{3}$ and $P_{4}$.

$$
\begin{aligned}
& P_{1}^{\prime \prime}=\frac{K_{j} \sin \theta_{j}}{2\left[1+\alpha_{1}^{\prime \prime}+\beta_{1}^{\prime \prime}\left(1+0,25 \alpha_{3}^{\prime}\right)\right]}=P_{1}^{\prime} \cdot \frac{\sin \theta_{j}}{\cos \theta_{j}}, \\
& P_{2}^{\prime \prime}=\frac{\alpha_{1}^{\prime \prime} K_{j} \sin \theta_{j}}{2\left[1+\alpha_{1}^{\prime \prime}+\beta_{1}^{\prime \prime}\left(1+0,25 \alpha_{3}^{\prime}\right)\right]}=P_{2}^{\prime} \cdot \frac{\sin \theta_{j}}{\cos \theta_{j}}, \\
& P_{3}^{\prime}=\frac{\beta_{1}^{\prime \prime} K_{j} \sin \theta_{j}}{2\left[1+\alpha_{1}^{\prime \prime}+\beta_{1}^{\prime \prime}\left(1+0,25 \alpha_{3}^{\prime}\right)\right]}=P_{3}^{\prime \prime} \cdot \frac{\sin \theta_{j}}{\cos \theta_{j}}, \\
& P_{4}^{\prime}=\frac{\alpha_{3}^{\prime} \beta_{1}^{\prime \prime} K_{j} \sin \theta_{j}}{4\left[1+\alpha_{1}^{\prime \prime}+\beta_{1}^{\prime \prime}\left(1+0,25 \alpha_{3}^{\prime}\right)\right]}=P_{4}^{\prime \prime} \cdot \frac{\sin \theta_{j}}{\cos \theta_{j}} .
\end{aligned}
$$


Stresses in the welds from the loads parallel to the chord caused by the load $K_{j}$ were as follows:

a) On the lengths $x_{j}$, when $P_{1}^{\prime}$ according to (4.1a):

$$
\sigma^{\prime}=0, \quad \dot{\tau_{\perp}}=\dot{\sigma_{\perp}}=\mathrm{O}, \quad \tau_{I I}^{\prime}=\frac{P_{1}^{\prime}}{A_{1}}
$$

b) On the lengths $b_{j, \text { eff }}$ or $b_{i, \text { eff }}$ (Fig. 7a or Fig. 7b), when $P_{2}^{\prime}$ according to (4.1b):

$$
\sigma^{\prime}=\frac{P_{2}^{\prime}}{A_{2}}, \quad \sigma_{\perp}^{\prime}=\sigma^{\prime} \sin \left(\theta_{j} / 2\right), \quad \tau_{\perp}^{\prime}=\sigma^{\prime} \cos \left(\theta_{j} / 2\right), \quad \tau_{I I}^{\prime}=0 .
$$

a)

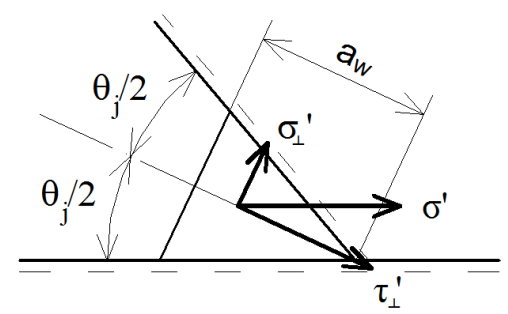

b)

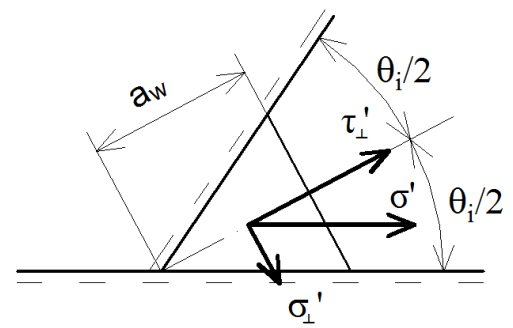

Fig. 7. Stresses in transverse welds of loads parallel to the chord

Stresses in the welds from loads perpendicular to the chord caused by the load $K_{j}$ were as follows:

a) on the lengths $x_{j}$, when $P_{1}^{\prime \prime}$ according to (4.2a):

a)

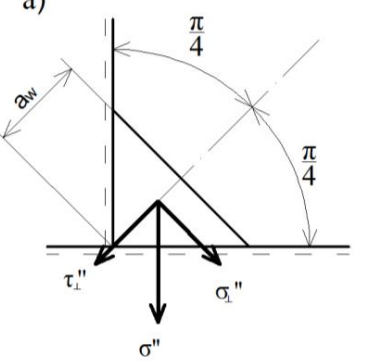

b)

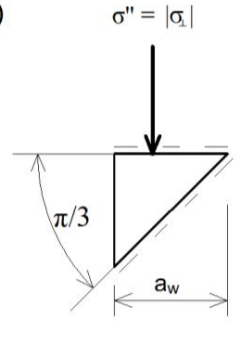

c)

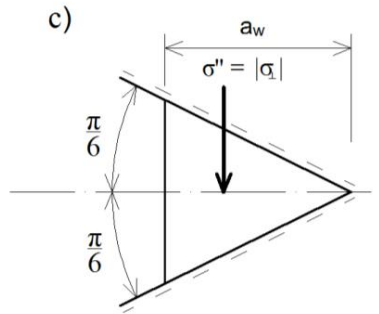

Fig. 8. Stresses in longitudinal welds of loads perpendicular to the chord 
- according to Fig. 8a):

$$
\sigma^{\prime \prime}=\frac{P_{1}^{\prime \prime}}{A_{1}}, \quad \sigma_{\perp}^{\prime \prime}= \pm \frac{\sigma^{\prime \prime}}{\sqrt{2}}, \quad \tau_{\perp}^{\prime \prime}= \pm \frac{\sigma^{\prime \prime}}{\sqrt{2}}, \quad \tau_{I I}^{\prime \prime}=0
$$

- according to Fig. 8b) or Fig. 8c):

$$
\sigma_{\perp}^{\prime \prime}=\sigma^{\prime \prime}, \quad \tau_{\perp}^{\prime \prime}=0 \quad, \quad \tau_{I I}^{\prime \prime}=0,
$$

a) on the lengths $b_{j, e f f}$ or $b_{i, e f f}$ (Fig. 9a or Fig. 9b), when $P_{2}^{\prime \prime}$ according to (4.2b):

$$
\sigma^{\prime \prime}=\frac{P_{2}^{\prime \prime}}{A_{2}}, \quad \sigma_{\perp}^{\prime \prime}=-\sigma^{\prime \prime} \cos \left(\theta_{j} / 2\right), \quad \tau_{\perp}^{\prime \prime}=\sigma^{\prime \prime} \sin \left(\theta_{j} / 2\right), \quad \tau_{I I}^{\prime \prime}=\sigma^{\prime \prime} .
$$

a)

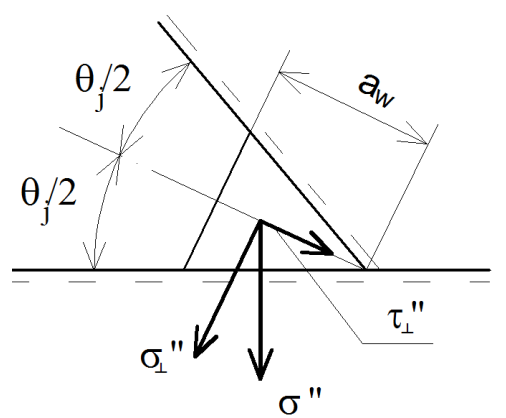

b)

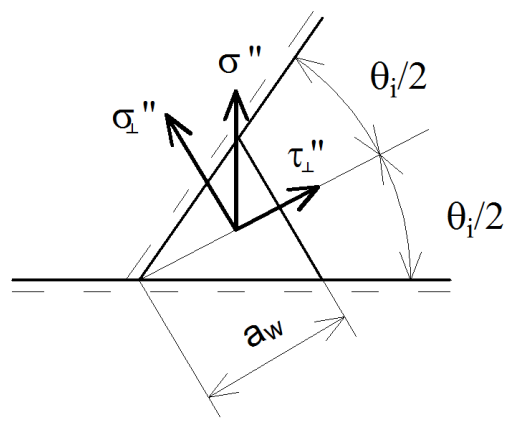

Fig. 9. Stresses in transverse welds of the load perpendicular to the chord 
a)

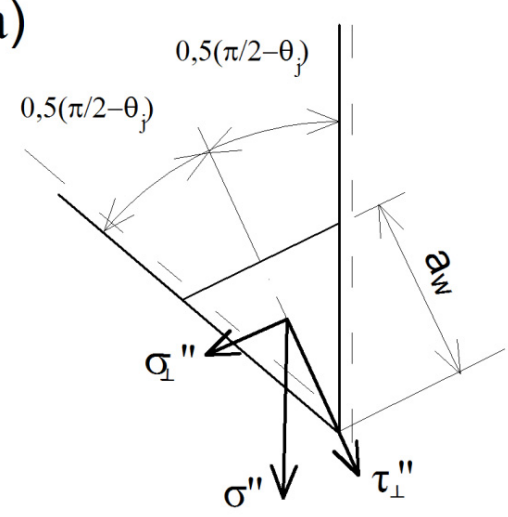

b)

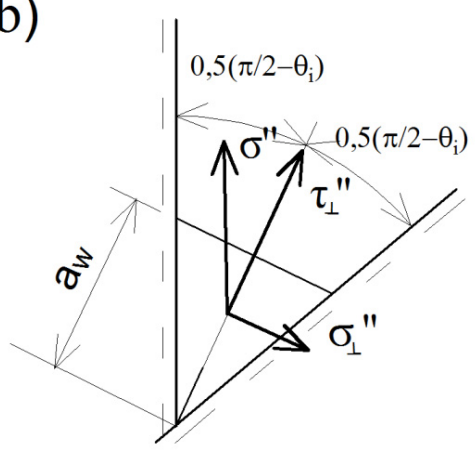

Fig. 10. Stresses in transverse welds of the load parallel to the rib plate

Stresses in the welds from the loads parallel to the rib caused by the load $K_{j}$ are as follows:

a) on the lengths $y_{j}$ or $y_{i}$, when $P_{3}^{\prime}$ according to $(4.2 \mathrm{c})$ :

$$
\sigma^{\prime}=0, \quad \dot{\sigma_{\perp}}=\dot{\tau_{\perp}}=\mathrm{O}, \quad \tau_{I I}^{\prime}=\frac{P_{3}^{\prime}}{A_{3}},
$$

b) on the lengths $b_{j}$, when $P_{4}^{\prime}$ according to (4.2d) (Fig. 10a or Fig. 10b):

$$
\sigma^{\prime}=\frac{P_{4}^{\prime}}{A_{4}}, \quad \sigma_{\perp}^{\prime}=-\sigma^{\prime} \sin 0,5\left(\pi / 2-\theta_{j}\right), \quad \tau_{\perp}^{\prime}=\sigma^{\prime} \cos 0,5\left(\pi / 2-\theta_{j}\right), \quad \tau_{I I}^{\prime}=0 .
$$

Stresses in the welds from the loads perpendicular to the rib caused by the load $K_{j}$ are as follows:

a) on the lengths $y_{j}$ or $y_{i}$, when $P_{3}^{\prime \prime}$ according to (4.1c):

$$
\sigma^{\prime \prime}=\frac{P_{3}^{\prime \prime}}{A_{3}}, \quad \sigma_{\perp}^{\prime \prime}= \pm \frac{\sigma^{\prime \prime}}{\sqrt{2}}, \quad \tau_{\perp}^{\prime \prime}= \pm \frac{\sigma^{\prime \prime}}{\sqrt{2}}, \quad \tau_{I I}^{\prime \prime}=\sigma^{\prime \prime},
$$

b) on the lengths $b_{j}$ or $b_{i}$, when $P_{4}^{\prime \prime}$ according to (4.1d) (Fig. 11a or Fig. 11b):

$$
\sigma^{\prime \prime}=\frac{P_{4}^{\prime \prime}}{A_{4}}, \quad \sigma_{\perp}^{\prime \prime}=\sigma^{\prime \prime} \cos 0,5\left(\pi / 2-\theta_{j}\right), \quad \tau_{\perp}^{\prime \prime}=\sigma^{\prime \prime} \sin 0,5\left(\pi / 2-\theta_{j}\right), \quad \tau_{I I}^{\prime \prime}=0 .
$$


a)

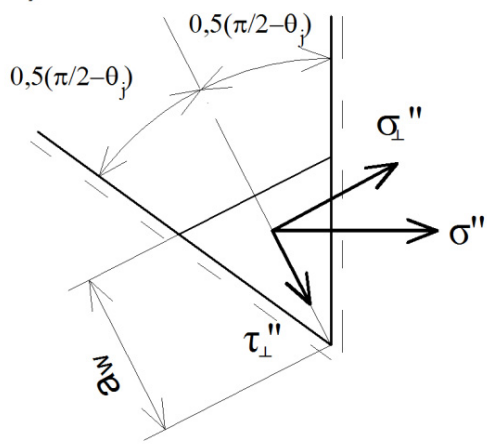

b)

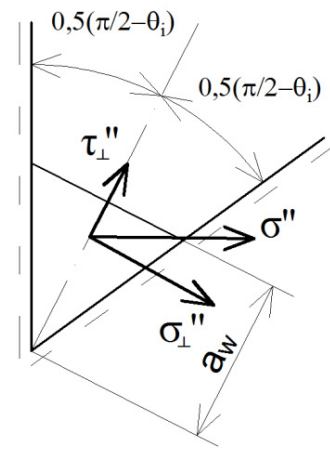

Fig. 11. Stresses in transverse welds of the load perpendicular to the rib plate

During the calculation of stresses in the welds, according to formulas (4.1) to (4.11) it is necessary during the consideration of force $K_{i}$ to use the overlapping brace substitute: $K_{i}$ instead of $K_{j}, \theta_{i}$ instead of $\theta_{j}, x_{i}$ instead of $x_{j}$ and $y_{i}$ instead of $y_{j}$. Moreover, during the consideration of the forces $P^{\prime}$ and $P^{\prime \prime}$ and the stresses $\sigma^{\prime}$ and $\sigma^{\prime \prime}$ it is necessary to change: $A_{j, x}$ to $A_{i, x}, A_{j, y}$ to $A_{i, y}, A_{j, b e f f}$ to $A_{i, b e f f}, A_{j, w}$ to $A_{i, w}$ and $A_{j, r}$ to $A_{i, r}$. One should also check the signs '+' or '-' in the formulas and choose them according to the direction of stress. In designing the joint with the rib it is necessary to shape the rib according to Fig. 12. This shape makes it possible to align the fillet weld in the corner of the chord.

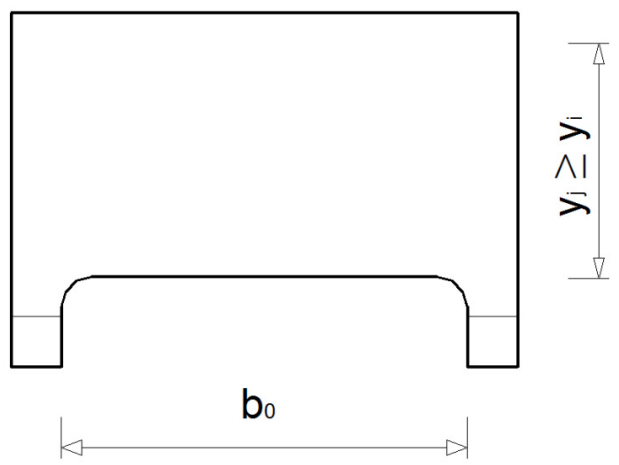

Fig. 12. Stresses in transverse welds of the load perpendicular to the rib plate 
Component of the stresses on the individual lengths of welds should be added together, remembering their characters:

$$
\sigma_{\perp}=\sigma_{\perp}^{\prime}+\sigma_{\perp}^{\prime \prime}, \tau_{\perp}=\tau_{\perp}^{\prime}+\tau_{\perp}^{\prime \prime}, \quad \tau_{I I}=\tau_{I I}^{\prime}+\tau_{I I}^{\prime \prime} .
$$

Then, in accordance with EN 1993-1-8 [8] we can assess the safety of the welds using the formulas:

$$
\sqrt{\sigma_{\perp}^{2}+3\left(\tau_{\perp}^{2}+\tau_{\|}^{2}\right)} \leq \frac{f_{u}}{\beta_{w} \cdot \gamma_{M 2}} \quad \text { and } \quad \sigma_{\perp} \leq 0,9 \frac{f_{u}}{\gamma_{M 2}}
$$

where:

$\beta_{w}-$ is the correlation factor of fillet welds,

$f_{u}$ - is the nominal ultimate tensile strength of steel,

$\gamma_{M 2}=1,25$ is the partial safety factor.

\subsubsection{SUPPORT JOINT WITH THE REINFORCING RIB PLATES}

When designing support joints with the reinforcing rib plates, it should be noted that:

- the post of the supporting joint corresponds to the chord of the intermediate joint,

- the upper chord plays the role of the brace loaded by the force $K_{j}$ or $K_{i}$ depending on whether the support is considered to be to the left or to the right of the support of a girder,

- the brace is loaded by the force $K_{i}$ or $K_{j}$,

- the angles $\theta \mathrm{j}$ and $\theta \mathrm{i}$ are between the braces,

- the angle $\left(\theta_{j} / 2\right)$ or $\left(\theta_{i} / 2\right)$, should be replaced respectively by an angle $(\pi / 2-\alpha)$ depending on whether the support is considered to the left or to the right of the support of a girder, where $\alpha$ is the angle that defines the slope of the roof.

When the rib plate has a $90^{\circ}$ incline by an angle $\alpha$, then in formulas (4.1) and (4.2) the correction should be carried out by multiplying the denominator enclosed in parentheses by $\cos \alpha$. A calculation of the support joint can then be performed as shown with respect to the intermediate joint, using formulas (4-12) to (4-13).

The support joints without the stiffening ribs can be calculated in the manner discussed previously, but this requires the interpolation of outgoing design situations which are already beyond the issues covered by this article. 


\subsection{THE JOINT MADE OF CIRCULAR HOLLOW SECTIONS}

\subsubsection{INTERMEDIATE JOINTS}

When shaping the joints of trusses made of rectangular or square hollow sections in the places of contact with those products outside the areas of the rounded corners, the designer has to deal with sections of straight lines. On the flat sections, butt or fillet welds can be carried out and in the corners, groove welds. In contrast, during the shaping of trusses and joints made of circular hollow sections, their mutual intersections lead to a spatial curve. The cutting of the braces according to a spatial curve is possible due to the use of modern gas-cutting units which are controlled by a computer. Cutting by using the approximate geometry is possible with a more labour intensive method, but this is rather expensive. During the manufacturing of the joints according to the spatial curve, at various sections the welds are similar to butt or fillet welds but at other sections the combination welds are applied. This requires the chamfering of sections of walls with a different angle of inclination. Units for gas cutting can trim the ends of the braces at the same time. This releases the designer, as well as the contractor from preparing burdensome documentation. The shape of the connection, as well as the volatility of the welds at different lengths makes it difficult to evaluate the resistance of such joints simply. In order to accurately estimate the resistance of such joints, a procedure presented in Sect. 4.1.1 with further changes is proposed.

The values of an overlap of the braces $q$ and $p$ are assessed in accordance with EN 1993-1-8, as indicated earlier. The values of lengths $x_{j}, x_{i}$ and $y_{j}, y_{i}$ are determined on the basis of joint drawings. The connection between the braces with the chord consists of two sections of spatial cylindrical lines with a shape similar to an ellipse, depending on the diameter of circular hollow sections and of their mutual angles of inclination (Fig. 13).

Measurement accuracy of these sections are evaluated according to:

$$
x_{j}+t_{p}+x_{i}=d_{j} / \sin \theta_{j}+p-q,
$$

The connection of the brace with a diameter $d_{j}$ with the chord will be analysed. Proceedings with respect to the second brace of diameter $d_{i}$ is the same; only requiring changing the associated geometric data. The perimeter of the spatial curve of contact of the joining elements shall be determined taking into account the English proposal:

$$
l_{e l}=l_{e l, 1}+l_{e l .2}+3\left(l_{e l, 1}^{2}+l_{e l, 2}^{2}\right)^{0,5},
$$


where:

$l_{e l, 1}=d_{j} / 2 \sin \theta_{j} \quad$ and $\quad l_{e l, 2}=\frac{d_{j}}{3} \cdot \frac{3-\left(d_{j} / d_{0}\right)^{2}}{2-\left(d_{j} / d_{0}\right)^{2}}$,
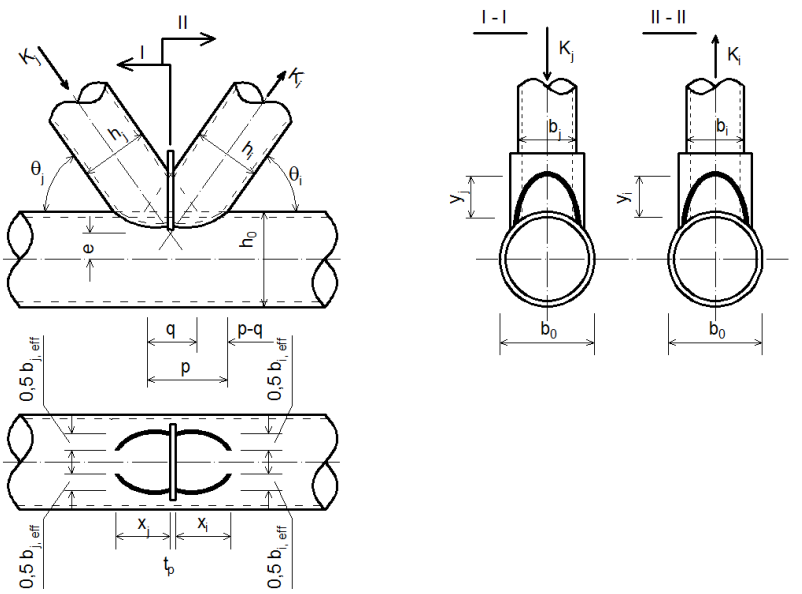

Fig. 13. Circular hollow section overlap joint with a reinforcing rib plate

The rib plate cuts off the part of the curve which cannot transfer the load from the brace to the chord. The value $x_{j}$ is used to assess the portion of the perimeter of the ellipse along the weld which connects the brace with the chord is placed. The effective length of the weld can be reduced due to the flexibility of the joint walls. It is assumed on the basis of the previous proposals of the authors that the following [3]:

$$
l_{w}=0,5(2+\pi) l_{e l} / \pi, \text { when } \theta_{j} \geq 60^{\circ},
$$

$$
l_{w}=l_{e l} \text {, when } \theta_{j} \leq 50^{\circ},
$$

(4.14c) $l_{w}$, is determined using linear interpolation of lengths calculated at angles $50^{\circ}$ and $60^{\circ}$,

Part of the perimeter of an ellipse, which is not involved in the load transfer from the brace to the chord is:

$$
\Delta l_{e l}=l_{e l} \cdot\left(1-x_{j} \cdot \sin \theta_{j} / d_{j}\right) .
$$

This part must be subtracted from the perimeter, determined from (4.14):

$$
l_{w c}=l_{w}-\Delta l_{e l} .
$$


The perimeter of the contact curve of the brace $d_{j}$ with the rib plate is determined by considering an ellipse with the semi-axes' lengths:

$$
a=0,5 d_{j} / \cos \theta_{j} \text { and } r_{j}=0,5 d_{j} .
$$

The perimeter of an ellipse with such semi-axes is determined by the formula, which gives a satisfactory approximation:

$$
l_{e l, p}=\pi\left(a+r_{j}\right)\left(1+\frac{3 c}{10+\sqrt{4-3 c}}\right),
$$

where: $c=\left(a-r_{j}\right)^{2} /\left(a+r_{j}\right)^{2}$.

For the initial assessment of the perimeter the following formula can be used:

$$
l_{e l, p}=\pi\left[1,5\left(a+r_{j}\right)-\sqrt{a \cdot r_{j}}\right\rfloor,
$$

Only a part of such determined welds transfers the load from the brace to the rib. The effective length can be calculated as follows:

$$
l_{e l, p, w}=\frac{\left(y_{j}+\Delta y\right) \cos \theta_{j}}{d_{j}} \cdot l_{e l, p},
$$

where $\Delta y$ is determined by the drawing of the joint; as the length of overlap between the brace and the chord and the overlapping cylinder on the chord cylinder. This length does not decrease, because the contact of the braces with the rib plate shows no flexibility. During the evaluation of the lengths of transverse welds, their linearisation is calculated in accordance with EN 1993-1-8. The contractual lengths of the welds in the place of contact between the brace with the chord and the rib plate are determined as follows:

$$
\begin{aligned}
& l_{1}=0,5\left(l_{w c}-\frac{\pi}{4} \cdot d_{j}\right)-1,4 a_{w p}, l_{2}=\frac{\pi}{4} \cdot 0,5 d_{j}, \\
& l_{3}=0,5\left(l_{e l, p, w}-\frac{\pi}{4} \cdot d_{j}\right)-1,4 a_{w}, l_{4}=\frac{\pi}{4} \cdot d_{j} .
\end{aligned}
$$

The procedure for checking the resistance is then the same as in Sect. 4.1.1. In the case where there is a reduction of the perimeter, this is varied out according to (4.14a) and (4.13c), in the formulas (4.1) and (4.2) the coefficient $\alpha_{1}{ }^{\prime}=\alpha_{1}{ }^{\prime \prime}=0$ should be taken. This leads to the fact that $P_{2}{ }^{\prime}=P_{2}^{\prime \prime}=0$. Thus $l_{2}=0, A_{2}=0$ while $l_{1}=0,5 l_{w c}$. The component stresses in the cross sections of the welds, located between the points at which the calculation was made using equations (4.8) through (4.11) are distributed around the perimeter of the semi ellipse. 


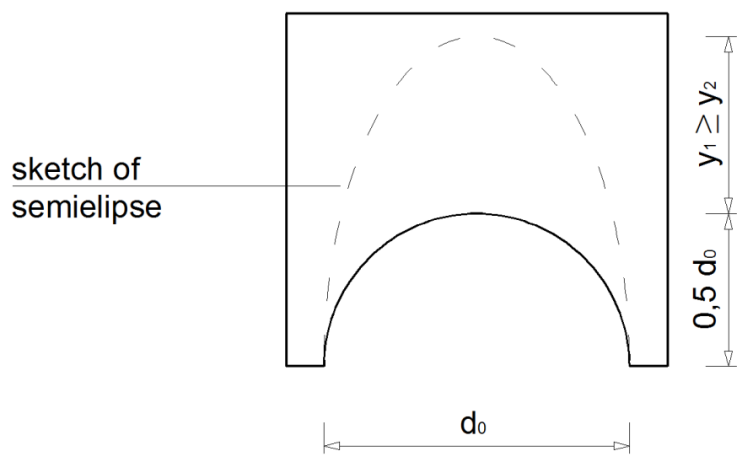

Fig. 14. Rib plate shape welded to the round chord

In the case of a joint with a reinforcing rib plate, the plate should be shaped in the form presented in Fig. 14 and customized to the diameter of the chord.

\subsubsection{SUPPORT JOINT}

The support joints of girders made of hollow sections are designed without the plates reinforcing the chords. The joints are made using butt, fillet or groove welds. It is recommended that the supporting elements should be designed using square hollow sections or $\mathrm{H}-$ sections. Calculations of such connections require a separate discussion.

\section{DESIGN EXAMPLE}

Consider the weld resistance truss members made of hot-rolled circular hollow sections (Fig. 15). Steel grade S275HN: $f_{y}=275 \mathrm{~N} / \mathrm{mm}^{2}, f_{u}=370 \mathrm{~N} / \mathrm{mm}^{2}$ (the thickness $t \leq 40 \mathrm{~mm}$ ). Chord: $d_{0}=139,7 \mathrm{~mm}, t_{0}=12 \mathrm{~mm}, A_{0}=24,0 \mathrm{~cm}, N_{0}=807,5 \mathrm{kN}$. Tension brace: $d_{j}=114,3 \mathrm{~mm}$, $t_{j}=8,8 \mathrm{~mm} ; N_{j . E d}=592,1 \mathrm{kN}$. Compression brace: $d_{i}=114,3 \mathrm{~mm}, t_{i}=8,8 \mathrm{~mm}, N_{i . E d}=-540,8 \mathrm{kN}$.

The angle between the chord and the tension brace $\theta_{j}=42^{\circ} 4^{\prime} 6^{\prime \prime}>30^{\circ}$, while the angle between the chord and the compression brace $\theta_{l}=47^{\circ} 7^{\prime} 6^{\prime \prime}>30^{\circ}\left(\sin \theta_{j}=0,6700, \sin \theta_{i}=0,7328\right.$, $\left.\cos \theta_{j}=0,7423, \cos \theta_{i}=0,6805\right)$.

Determining an overlap value 
Assuming $e=-50 \mathrm{~mm}$. Hence the overlap is:

$$
\begin{aligned}
& q=\left(e+\frac{d_{0}}{2}\right) \frac{\sin \left(\theta_{i}+\theta_{j}\right)}{\sin \theta_{i} \sin \theta_{j}}-\frac{d_{i}}{2 \sin \theta_{i}}-\frac{d_{j}}{2 \sin \theta_{j}}= \\
& =\left(-50+\frac{139,7}{2}\right) \frac{1,0}{0,7328 \cdot 0,6700}-\frac{114,3}{2 \cdot 0,7328}-\frac{114,3}{2 \cdot 0,6700}=-122,9 \mathrm{~mm},
\end{aligned}
$$

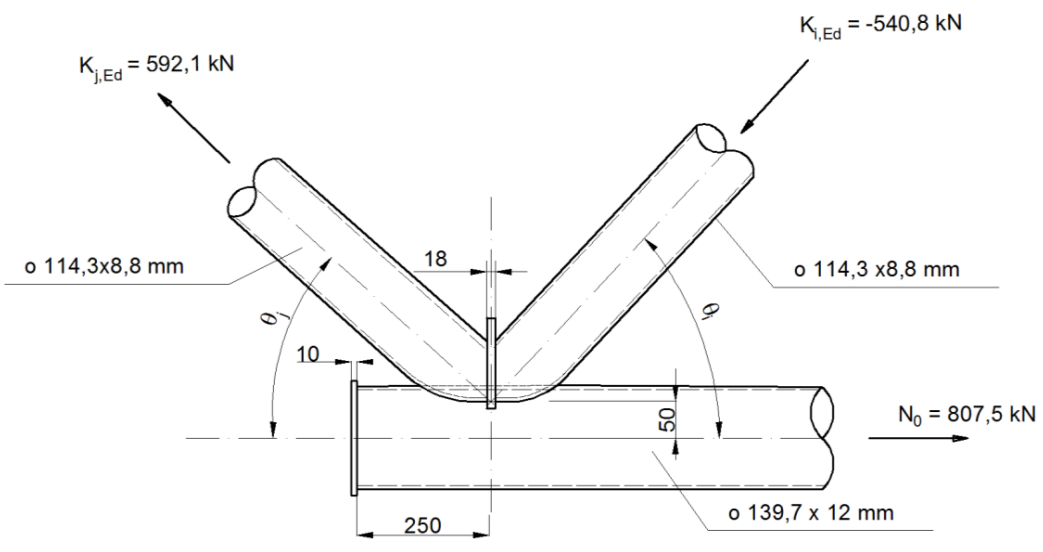

Fig. 15. Joint made of CHS

$$
\begin{aligned}
& p=h_{i} / \sin \theta_{i}=114,3 / 0,7328=156,0 \mathrm{~mm}, \\
& \lambda_{o v}=(q / p) \cdot 100 \%=(122,9 / 156,0) \cdot 100 \%=78,8 \% .
\end{aligned}
$$

On the base of Fig. 15 we obtain: $x_{j}=95,0 \mathrm{~mm}, x_{i}=91,5 \mathrm{~mm}, y_{j}=69,5 \mathrm{~mm}, y_{i}=70,0 \mathrm{~mm}$, $\Delta y=27,0 \mathrm{~mm}$.

Checking the distribution of the lengths of welds between the brace and the chord: $x_{j}+t_{p}+x_{i}=95+18+91,5=204,5 \mathrm{~mm} \approx d_{j} / \sin \theta_{j}+p-q=114,3 / 0,67+156-122,9=$

$$
=203,7 \mathrm{~mm} \text {. }
$$

The difference is $0,4 \%$, so the result is correct.

Determining the thickness of the weld:

$$
a_{w, \max }=0,986 t_{i}=0,986 \cdot 8,8=8,7 \mathrm{~mm} .
$$

Assumed thickness of welds: $a_{w}=a_{w, p}=8,0 \mathrm{~mm}<8,7 \mathrm{~mm}$. 
A length of the diameter of an elliptical splice plate of the brace with the chord

$$
\begin{aligned}
& l_{e l}=l_{e l, 1}+l_{e l, 2}+3\left(l_{e l, 1}^{2}+l_{e l, 2}^{2}\right)^{0,5}, \text { wherein } \\
& l_{e l, 1}=d_{j} / 2 \sin \theta_{j}=\frac{114,3}{2 \cdot 0,67}=85,3 \mathrm{~mm}, \\
& l_{e l, 2}=\frac{d_{j}}{3} \cdot \frac{3-\left(d_{j} / d_{0}\right)^{2}}{2-\left(d_{j} / d_{0}\right)^{2}}=\frac{114,3}{3} \cdot \frac{3-(114,3-135,7)^{2}}{2-(114,3-139,7)^{2}}=66,7 \mathrm{~mm}, \\
& l_{e l}=85,3+66,7+3\left(85,3^{2}+66,7^{2}\right)^{0,5}=476,8 \mathrm{~mm}, \\
& \Delta l_{e l}=l_{e l} \cdot\left(1-x_{j} \cdot \sin \theta_{j} / d_{j}\right)=476,8 \cdot(1-95,0 \cdot 0,67 / 114,3)=211,3 \mathrm{~mm} . \\
& l_{w}=l_{e l}=476,8 \mathrm{~mm}, \\
& l_{w c}=l_{w}-\Delta l_{e l}=476,8-211,3=265,5 \mathrm{~mm} .
\end{aligned}
$$

Lengths of welds at $d_{j}$, as there is no reduction:

$$
\begin{aligned}
& l_{2}=\frac{\pi}{4} \cdot 0,5 d_{j}=\frac{3,14}{4} \cdot 0,5 \cdot 114,3=44,9 \mathrm{~mm}, \\
& l_{1}=0,5\left(l_{w c}-\frac{\pi}{4} \cdot d_{j}\right)-1,4 a_{w p}=0,5\left(265,5-\frac{3,14}{4} \cdot 114,3\right)-1,4 \cdot 8=76,7 \mathrm{~mm} .
\end{aligned}
$$

The length of the diameter of the elliptical splice of the brace with the rib plate

$$
\begin{aligned}
& a=0,5 d_{j} / \cos \theta_{j}=0,5 \cdot 114,3 / 0,7423=77.0 \mathrm{~mm}, \\
& r_{j}=0,5 d_{j}=0,5 \cdot 114,3=57,15 \mathrm{~mm}, \\
& l_{e l, p}=\pi\left[1,5\left(a+r_{j}\right)-\sqrt{a \cdot r_{j}}\right\rfloor=3,14[1,5(77,0+57,15)-\sqrt{77 \cdot 57,15}]=423,5 \mathrm{~mm}, \\
& l_{e l, p, w}=\frac{\left(y_{j}+\Delta y\right) \cos \theta_{j}}{d_{j}} \cdot l_{e l, p}=\frac{(69,5+27,0) \cdot 0,7423}{114,3} \cdot 423,5=265,4 \mathrm{~mm} .
\end{aligned}
$$

The lengths of welds connecting the brace with the rib plate:

$$
\begin{aligned}
& l_{4}=\frac{\pi}{4} \cdot d_{j}=\frac{3,14}{4} \cdot 114,3=89,7 \mathrm{~mm}, \\
& l_{3}=0,5\left(l_{e l, p, w}-\frac{\pi}{4} \cdot d_{j}\right)-1,4 a_{w}=0,5\left(265,4-\frac{3,14}{4} \cdot 114,3\right)-1,4 \cdot 8=76,6 \mathrm{~mm} .
\end{aligned}
$$

Cross-sectional areas of the welds:

$$
\begin{aligned}
& A_{w 1}=l_{1} a_{w}=76,7 \cdot 8=613,6 \mathrm{~mm}^{2}, \quad A_{w 2}=l_{2} a_{w,}=44,9 \cdot 8=359,2 \mathrm{~mm}^{2}, \\
& A_{w 3}=l_{3} a_{w}=76,6 \cdot 8=612,8 \mathrm{~mm}^{2}, \quad A_{w 4}=l_{4} a_{w}=89,7 \cdot 8=717,6 \mathrm{~mm}^{2} .
\end{aligned}
$$


Auxiliary coefficients:

$\alpha_{1}^{\prime}=\frac{A_{w 2}}{A_{w 1}}=\frac{359,2}{613,6}=0,585, \alpha_{3}^{\prime \prime}=\frac{2 A_{w 4}}{A_{w 3}}=\frac{2 \cdot 717,6}{612,8}=2,34, \beta_{1}^{\prime}=\frac{A_{w 3}}{A_{w 1}}=\frac{612,8}{613,6}=0,999$.

The forces acting on the individual lengths of welds:

$$
\begin{aligned}
& P_{1}^{\prime}=\frac{N_{j, E d} \cos \theta_{j}}{2\left[1+\alpha_{1}^{\prime}+\beta_{1}^{\prime}\left(1+0,25 \alpha_{3}^{\prime \prime}\right)\right]}=\frac{592,1 \cdot 0,7423}{2[1+0,585+0,999(1+0,25 \cdot 2,34)]}=69,4 \mathrm{kN}, \\
& P_{2}^{\prime}=\frac{\alpha_{1}^{\prime} \cdot N_{j, E d} \cos \theta_{j}}{2\left[1+\alpha_{1}^{\prime}+\beta_{1}^{\prime}\left(1+0,25 \alpha_{3}^{\prime \prime}\right)\right]}=\frac{0,585 \cdot 592,1 \cdot 0,7423}{2[1+0,585+0,999(1+0,25 \cdot 2,34)]}=40,6 \mathrm{kN}, \\
& P_{3}^{\prime \prime}=\frac{\beta_{1}^{\prime} \cdot N_{j, E d} \cos \theta_{j}}{2\left[1+\alpha_{1}^{\prime}+\beta_{1}^{\prime}\left(1+0,25 \alpha_{3}^{\prime \prime}\right)\right]}=\frac{0,999 \cdot 592,1 \cdot 0,7423}{2[1+0,585+0,999(1+0,25 \cdot 2,34)]}=69,3 \mathrm{kN}, \\
& P_{4}^{\prime \prime}=\frac{\alpha_{3}^{\prime \prime} \cdot \beta_{1}^{\prime} \cdot N_{j . E d} \cos \theta_{j}}{4\left[1+\alpha_{1}^{\prime}+\beta_{1}^{\prime}\left(1+0,25 \alpha_{3}^{\prime \prime}\right)\right]}=\frac{2,34 \cdot 0,999 \cdot 592,1 \cdot 0,7423}{4[1+0,585+0,999(1+0,25 \cdot 2,34)]}=81,1 \mathrm{kN}, \\
& P_{1}^{\prime \prime}=P_{1}^{\prime} \frac{\sin \theta_{j}}{\cos \theta_{j}}=69,4 \frac{0,67}{0,7423}=69,4 \cdot 0,9026=62,6 \mathrm{kN}, \\
& P_{2}^{\prime \prime}=P_{2}^{\prime} \frac{\sin \theta_{j}}{\cos \theta_{j}}=40,6 \cdot 0,9026=36,6 \mathrm{kN}, \\
& P_{3}^{\prime}=P_{3}^{\prime \prime} \frac{\sin \theta_{j}}{\cos \theta_{j}}=69,3 \cdot 0,9026=62,6 \mathrm{kN}, \\
& P_{4}^{\prime}=P_{4}^{\prime \prime} \frac{\sin \theta_{j}}{\cos \theta_{j}}=81,1 \cdot 0,9026=73,2 \mathrm{kN} .
\end{aligned}
$$

Due to the fact that these forces may act in different directions than calculated using design formulas, it is necessary to check their marks.

Stresses in welds with loads parallel to the chord:

a) The sections of length $l_{l}$ :

$$
\sigma^{\prime}=0, \quad \tau_{\perp}^{\prime}=\sigma_{\perp}^{\prime}=0, \quad \tau_{I I}^{\prime}=\frac{P_{1}^{\prime}}{A_{w 1}}=\frac{69,4 \cdot 10^{3}}{613,6}=113,1 \mathrm{MPa},
$$

b) The sections of length $l_{2}$ :

$$
\begin{aligned}
& \sigma^{\prime}=\frac{P_{2}^{\prime}}{A_{w 2}}=\frac{40,6 \cdot 10^{3}}{359,2}=113,0 \mathrm{MPa}, \quad \tau_{\mathrm{II}}^{\prime}=0, \\
& \sigma_{\perp}^{\prime}=-\sigma^{\prime} \sin \left(\theta_{j} / 2\right)=-113,0 \cdot 0,3589=-40,6 \mathrm{MPa}, \\
& \tau_{\perp}^{\prime}=-\sigma^{\prime} \cos \left(\theta_{j} / 2\right)=-113,0 \cdot 0,9334=-105,5 \mathrm{MPa} .
\end{aligned}
$$


Stresses in welds with loads perpendicular to the chord:

a) The sections of length $l_{1}$ :

$$
\begin{aligned}
& \sigma^{\prime \prime}=\frac{P_{1}^{\prime \prime}}{A_{w 1}}=\frac{62,6 \cdot 10^{3}}{613,6}=102,0 \mathrm{MPa}, \quad \tau_{I I}^{\prime \prime}=0, \\
& \sigma_{\perp}^{\prime \prime}=\tau_{\perp}^{\prime \prime}= \pm \frac{\sigma^{\prime \prime}}{\sqrt{2}}= \pm \frac{102,0}{\sqrt{2}}=72,1 \mathrm{MPa},
\end{aligned}
$$

b) The sections of length $l_{2}$ :

$$
\begin{aligned}
& \sigma^{\prime \prime}=\frac{P_{2}^{\prime \prime}}{A_{w 2}}=\frac{36,6 \cdot 10^{3}}{359,2}=101,9 \mathrm{MPa}, \quad \tau_{I I}^{\prime \prime}=\sigma^{\prime \prime}, \\
& \sigma_{\perp}^{\prime \prime}=\sigma^{\prime \prime} \cos \left(\theta_{j} / 2\right)=101,9 \cdot 0,9334=95,1 \mathrm{MPa}, \\
& \tau_{\perp}^{\prime \prime}=-\sigma^{\prime \prime} \sin \left(\theta_{j} / 2\right)=-101,9 \cdot 0,3589=-36,6 \mathrm{MPa} .
\end{aligned}
$$

Stresses in welds with loads parallel to the rib:

a) The sections of length $l_{3}$ :

$$
\sigma^{\prime}=0, \quad \dot{\sigma}_{\perp}^{\prime}=\dot{\tau}_{\perp}^{\prime}=\mathrm{O}, \quad \tau_{I I}^{\prime}=\frac{P_{3}^{\prime}}{A_{w 3}}=\frac{62,6 \cdot 10^{3}}{612,8}=102,2 \mathrm{MPa},
$$

b) The sections of length $l_{4}$ :

$$
\begin{aligned}
& \sigma^{\prime}=\frac{P_{4}^{\prime}}{A_{w 4}}=\frac{73,2 \cdot 10^{3}}{717,6}=102,0 \mathrm{MPa}, \quad \tau_{I I}^{\prime}=0, \\
& \sigma_{\perp}^{\prime}=\sigma^{\prime} \sin 0,5\left(\pi / 2-\theta_{j}\right)=102,0 \cdot \sin \left(\frac{\pi}{4}-\frac{42^{\circ} 4^{\prime} 6^{\prime \prime}}{2}\right)=102,0 \cdot 0,0511=5,2 \mathrm{MPa}, \\
& \tau_{\perp}^{\prime}=-\sigma^{\prime} \cos 0,5\left(\pi / 2-\theta_{j}\right)=-102,0 \cdot \cos \left(\frac{\pi}{4}-\frac{42^{\circ} 4^{\prime} 6^{\prime \prime}}{2}\right)=-102,0 \cdot 0,9987=-101,7 \mathrm{MPa} .
\end{aligned}
$$

Stresses in welds with loads perpendicular to the rib:

a) The sections of length $l_{3}$ :

$$
\begin{aligned}
& \sigma^{\prime \prime}=\frac{P_{3}^{\prime \prime}}{A_{w 3}}=\frac{69,3 \cdot 10^{3}}{612,8}=113,1 \mathrm{MPa}, \quad \tau_{I I}^{\prime \prime}=0, \\
& \sigma_{\perp}^{\prime \prime}=\tau_{\perp}^{\prime \prime}= \pm \frac{\sigma^{\prime \prime}}{\sqrt{2}}= \pm \frac{113,1}{\sqrt{2}}= \pm 80,0 \mathrm{MPa},
\end{aligned}
$$

b) The sections of length $l_{4}$ :

$$
\sigma^{\prime \prime}=\frac{P_{4}^{\prime \prime}}{A_{w 4}}=\frac{81,1 \cdot 10^{3}}{717,6}=113,0 \mathrm{MPa}, \quad \tau_{I I}^{\prime \prime}=0,
$$




$$
\begin{aligned}
& \sigma_{\perp}^{\prime \prime}=-\sigma \cos 0,5\left(\pi / 2-\theta_{j}\right)=-113,0 \cdot 0,9987=-112,9 \mathrm{MPa}, \\
& \tau_{\perp}^{\prime \prime}=-\sin 0,5\left(\pi / 2-\theta_{j}\right)=-113,0 \cdot 0,0511=-5,8 \mathrm{MPa} .
\end{aligned}
$$

Resultant stresses in welds of the component forces:

a) The sections of length $l_{l}$ :

$$
\begin{aligned}
& \sigma_{\perp}=\sigma_{\perp}^{\prime}+\sigma_{\perp}^{\prime \prime}=0+72,1=72,1 \mathrm{MPa}, \\
& \tau_{\perp}=\tau_{\perp}^{\prime}+\tau_{\perp}^{\prime \prime}=0+72,1=72,1 \mathrm{MPa}, \\
& \tau_{\|}=\tau_{\|}^{\prime}+\tau_{\|}^{\prime \prime}=113,1+0=113,1 \mathrm{MPa},
\end{aligned}
$$

a) The sections of length $l_{2}$ :

$$
\begin{aligned}
& \sigma_{\perp}=\sigma_{\perp}^{\prime}+\sigma_{\perp}^{\prime \prime}=-40,6+95,1=54,5 \mathrm{MPa}, \\
& \tau_{\perp}=\tau_{\perp}^{\prime}+\tau_{\perp}^{\prime \prime}=-105,5-36,6=-141,7 \mathrm{MPa}, \\
& \tau_{\|}=\tau_{\|}^{\prime}+\tau_{\|}^{\prime \prime}=0+101,9=101,9 \mathrm{MPa},
\end{aligned}
$$

b) The sections of length $l_{3}$ :

$$
\begin{aligned}
& \sigma_{\perp}=\sigma_{\perp}^{\prime}+\sigma_{\perp}^{\prime \prime}=0+80,0=80,0 \mathrm{MPa}, \\
& \tau_{\perp}=\tau_{\perp}^{\prime}+\tau_{\perp}^{\prime \prime}=0+80,0=80,0 \mathrm{MPa}, \\
& \tau_{\|}=\tau_{\|}^{\prime}+\tau_{\|}^{\prime \prime}=102,2+0=102,2 \mathrm{MPa},
\end{aligned}
$$

c) The sections of length $l_{4}$ :

$$
\begin{aligned}
& \sigma_{\perp}=\sigma_{\perp}^{\prime}+\sigma_{\perp}^{\prime \prime}=5,2-112,9=-107,7 \mathrm{MPa}, \\
& \tau_{\perp}=\tau_{\perp}^{\prime}+\tau_{\perp}^{\prime \prime}=-101,7-5,8=-107,5 \mathrm{MPa}, \\
& \tau_{\|}=\tau_{\|}^{\prime}+\tau_{\|}^{\prime \prime}=0+0=0 .
\end{aligned}
$$

Checking the safety of the welds

a) The sections of length $l_{l}$ :

$$
\left[\sigma_{\perp}^{2}+3\left(\tau_{\perp}^{2}+\tau_{\|}^{2}\right)\right]^{0,5}=\left[72,1^{2}+3\left(72,1^{2}+113,1^{2}\right)\right]^{0,5}=243,2 \mathrm{MPa}<
$$$$
\frac{f_{u}}{\beta_{w} \gamma_{M w}}=\frac{370}{0,9 \cdot 1,25}=328,9 \mathrm{MPa} \text {, }
$$$$
\sigma_{\perp}=72,1 \mathrm{MPa}<\frac{0,9 \cdot 370}{1,25}=266,4 \mathrm{MPa} .
$$

b) The sections of length $l_{2}$ :

$$
\left[\sigma_{\perp}^{2}+3\left(\tau_{\perp}^{2}+\tau_{\|}^{2}\right)\right]^{0,5}=\left[54,4^{2}+3\left((-141,7)^{2}+101,9^{2}\right)\right]^{0,5}=307,2 \mathrm{MPa}<
$$




$$
\begin{aligned}
& \frac{f_{u}}{\beta_{w} \gamma_{M w}}=\frac{370}{0,9 \cdot 1,25}=328,9 \mathrm{MPa}, \\
& \sigma_{\perp}=54,4 \mathrm{MPa}<\frac{0,9 \cdot 370}{1,25}=266,4 \mathrm{MPa} .
\end{aligned}
$$

Reserve of resistance:

$$
\frac{328,9-307,2}{328,9} \cdot 100 \%=6,6 \% \text {. }
$$

c) The sections of length $l_{3}$ :

$$
\begin{aligned}
& {\left[\sigma_{\perp}^{2}+3\left(\tau_{\perp}^{2}+\tau_{\|}^{2}\right)\right]^{0,5}=\left[80,0^{2}+3\left(80,0^{2}+102,2^{2}\right)\right]^{0,5}=238,6 \mathrm{MPa}<} \\
& \frac{f_{u}}{\beta_{w} \gamma_{M w}}=\frac{370}{0,9 \cdot 1,25}=328,9 \mathrm{MPa}, \\
& \sigma_{\perp}=80,0 \mathrm{MPa}<\frac{0,9 \cdot 370}{1,25}=266,4 \mathrm{MPa} .
\end{aligned}
$$

d) The sections of length $l_{4}$ :

$$
\begin{aligned}
& {\left[\sigma_{\perp}^{2}+3\left(\tau_{\perp}^{2}+\tau_{\|}^{2}\right)\right]^{0,5}=\left[(-107,7)^{2}+3\left((-107,5)^{2}+0^{2}\right)\right]^{0,5}=215,1 \mathrm{MPa}<} \\
& \frac{f_{u}}{\beta_{w} \gamma_{M w}}=\frac{370}{0,9 \cdot 1,25}=328,9 \mathrm{MPa}, \\
& \sigma_{\perp}=107,7 \mathrm{MPa}<\frac{0,9 \cdot 370}{1,25}=266,4 \mathrm{MPa} .
\end{aligned}
$$

A reserve of the connection resistance of the tension brace $N_{j . E d}=592,1 \mathrm{kN}$ with the chord on the length $l_{2}$ is only $6,6 \%$. Due to the estimated character of the assessment of the effective lengths, the co-authors recommend to reserve about $15 \%$. By increasing the weld thickness to $a_{w, \max }=8,7 \mathrm{~mm}$, we obtain the reserve of about $13 \%$. In order to harmonize the connection, the thickness of the weld should be equal to $a_{w, \max }=9 \mathrm{~mm} \equiv 8,7 \mathrm{~mm}$. After the calculation of the second brace loaded by the force $N_{i . E d}=-540,8 \mathrm{kN}$, it was found that the resistance reserve in the weld $l_{2}$ is $11 \%$. If the thickness of the weld increases to $8,5 \mathrm{~mm}$, the resistance reserve will be equal $16 \%$. It would be sufficient, but in order to standardize, all fillet welds in the joint should have the thickness $a_{w, \max }=9 \mathrm{~mm}$. 


\section{REFERENCES}

1. Bródka J. Design of joint made of hollow sections with reinforced rib. Joint resistance. International PolishUkrainian Scientific Conference. Gdansk 2014.

2. Bródka J., Broniewicz M.: Calculation of welded joints of trusses made of rectangular hollow sections. - Steel Construction, 2002, no. 4.

3. Bródka J., Broniewicz M.: Assessing of capacity of welded connections from hollow sections according to EN 1993-1-8. - Steel Construction, 2007, no. 1.

4. Bródka J., Broniewicz M.: Calculation of welding trusses overlap joints made of rectangular hollow sections. Archives of Civil Engineering. 2013, No. 4.

5. Bródka J., Kozłowski A., Ligocki I., Łaguna J., Ślęczka L.: Design and calculation of connections and joints of steel structures. Vol 1. Second edition, PWT. Rzeszow 2013.

6. BS ISO 14346:2013 Welding - static design procedure for hollow section joints. Recommendations.

7. Frater. G. S., Packer J. A.: Design of Filled Weldments for Hollow Structural Section Trusses. CIDECT Report No5AN/2 and IIW Doc. SC-XV-E-90=166.

8. EN 1090-2: 2008 Execution of steel structures and aluminium structures. Technical requirements for steel structures.

9. EN 1993-1-8: Eurocode 3. Design of steel structures. Design of joints.

10. EN 10210: 2006 Hot finished structural hollow sections of non-alloy and fine grain steels. Part 1 Technical delivery requirements. Part 2 Tolerances, dimensions and sectional properties.

11. EN 10219: 2006 Cold formed welded structural hollow sections of non-alloy and fine grain steels. Part 1 Technical delivery requirements. Part 2 Tolerances, dimensions and sectional properties.

12. Static design procedure for welded hollow section joints. Recommendations. (2009), 3rd Edition. International Institute of Welding. Commission XV, IIW. Doc. XV-1039-09. 